\title{
El espacio público dictatorial: edificios y lugares significados por el poder político.
} Dictatorial public space: buildings and places signified by political power.

Robinson Silva Hidalgo

\section{Filiación}

Universidad Austral de Chile

E mail: robinson.silva@uach.cl

Primera versión recibida en: 15 de marzo de 2014

Última versión recibida en: 15 de junio de 2014

\section{Resumen}

Este artículo plantea reflexiones acerca de las restricciones que la última dictadura militar le impuso al espacio público. A través del análisis histórico de las transformaciones en la nomenclatura, los geosímbolos políticos, representados en La Moneda, las casas de Allende y Pinochet, y los espacios ocupados por el régimen, nos adentramos en las características que asumió el espacio público intervenido.

Luego de la revisión histórica, se establecen algunas conclusiones referidas al impacto que estos cambios tuvieron en el espacio público en el marco de una transgresión al estado de derecho y a la democracia.

\section{Palabras claves}

Espacio público; dictadura; nomenclatura; geosímbolos; intervención.

\begin{abstract}
This article raises reflections about the restrictions that the last military dictatorship imposed on the public space. Through the historical analysis of the transformations in the nomenclature, the geosymbols political, represented in La Moneda, the houses of Allende and Pinochet, and the spaces occupied by the regime, we delve into the characteristics that took over the public space involved.

After the historical review, laying down some conclusions regarding the impact that these changes were in the public space in the framework of a violation of the rule of law and democracy.
\end{abstract}

\section{Key words}

Public space; dictadorship; nomenclature; geosymbols; intervention.

\section{Sumario}

Introducción

1 El proyecto urbano en perspectiva estratégica

2 Perspectivas Estratégicas y Miradas Tácticas

Conclusiones: Relevancia de un enfoque crítico y reflexivo.

Bibliografía 


\section{Presentación}

Este trabajo analizará una categoría de especial interés para la investigación histórica: el espacio público. Revisaremos aspectos sensibles y discutidos que aparecen en las fuentes, fundamentalmente en la prensa -oficialista y de oposición- que hemos utilizado prioritariamente para el artículo que se presenta aquí. Nos interesa entregar algunos aspectos del carácter que tuvo el uso del espacio público, por parte de la última dictadura militar chilena (1973-1989), para ello desarrollaremos en tres apartados algunos de los aspectos significativos sobre tal cuestión.

En cuanto a los puntos que trataremos, primero abordaremos la nomenclatura dictatorial, pues se produjeron múltiples cambios en la denominación de los espacios públicos durante la dictadura. En un segundo punto, nos detendremos en el carácter geosimbólico del Palacio de La Moneda, estudiando el devenir de ese espacio reconocido por los chilenos como el centro de la administración política. En el tercer apartado analizaremos la aproximación del régimen dictatorial a las casas presidenciales, espacios polémicos por diversidad de razones, tanto para el caso del presidente Allende, como para las residencias de Augusto Pinochet. Finalmente, abordaremos lo relativo a los espacios ocupados y significados con predilección por parte del régimen.

Con este abordaje pretendemos caracterizar aquellos lugares en los que la dictadura volcó y plasmó materialmente los mensajes que quiso que la ciudadanía asumiera como su propio proyecto político de Estado nacional. Los espacios públicos representan los lugares desde donde se emite el discurso político; es por ello que nos interesa de sobremanera entender el carácter de las intervenciones sobre él. Durante la dictadura se reafirmó la apropiación material e ideológica de elementos propios de los espacios de uso público; por lo tanto, podemos rastrear las huellas del proyecto ideológico y político que el régimen militar impregnó en los diversos edificios, monumentos, calles, plazas y una diversa tipología de lugares que expresaron esta idea.

\section{La nomenclatura dictatorial}

A continuación profundizaremos el tratamiento relativo a las políticas que generó el régimen en relación a las denominaciones y nombramientos sobre el espacio público. Con ello buscamos referir las marcas ideológicas que se expresaron en el paisaje urbano de este período.

Nombrar un lugar es conocerlo (Bonfil, 1989), ello implica también una apropiación del mismo; desde esta práctica colonizadora podemos colegir las ideas que los grupos en el poder desean imponer como hegemónicas. Aquí veremos los cambios introducidos en comunas, poblaciones, barrios, calles y espacios de uso público. Así, revisaremos el nombre de esos lugares, que tuvieron relación directa con los sucesos de 1973 y los eventos que políticamente significaron hechos importantes para la historia de la dictadura y, por lo tanto, del país.

A través de bandos se cambiaron los nombres de campamentos y poblaciones establecidos en el período de la Unidad Popular. La sustitución se hizo aduciendo que la nomenclatura de los barrios aludía a personas que no habían aportado nada a la sociedad y que, además, las denominaciones eran extranjerizantes. Estos nombres obedecían a identificaciones con procesos revolucionarios del siglo XX, tanto chilenos como internacionales.

Uno de estos cambios se produjo por medio de un bando de la segunda zona naval de Talcahuano. El texto, que denominó a campamentos y tomas de terreno de dicha comuna como "poblaciones", reiteró lo dicho arriba, que los nombres existentes correspondían a personas escasamente relevantes. El bando dio cuenta de los cambios ordenados por el jefe de la 
segunda zona naval, Jorge Paredes Wentzel, y señaló detalladamente los nuevos nombres de los dieciocho ex campamentos y tomas de terreno de esa comuna:

[...] en el día de las glorias de la Patria, es de toda conveniencia y necesidad borrar definitivamente todo vestigio que en cualquier forma no contribuya a hermanar a los chilenos. // Los nuevos nombres atañen al campamento Estanislao Montoya, que se Ilamará población Eleuterio Ramírez, Campamento Lenin por población Diego Portales; Población Puerto Montt por población Patricio Lynch; Campamento Luciano Cruz por población José Miguel Carrera; Campamento Por la razón o la Fuerza por población Javiera Carrera; Campamento José Tohá por población Jorge Montt; campamento Fidel castro por población General Baquedano; campamento Hernán del Canto por población sargento Aldea; campamento Inti Peredo por población Eusebio Lillo; toma el Pajonal por población El Pajonal; toma San Francisco por población San Francisco; toma Villa Tatín por población Vista Hermosa; toma Laguna Partal por población Partal; toma 18 de septiembre por población 18 de septiembre; toma villa palitos por población Los Palitos y campamento El manzano por población El Manzano. ${ }^{1}$

En 1976 se estableció una normativa para el nombramiento de los espacios públicos, la nueva legislación se hizo, según la autoridad dictatorial, en función de las necesidades de ordenamiento urbano y despojado de razones ideológicas. Hacia mediados y fines de la dictadura no se utilizaron denominaciones ligadas a la historia nacional, pues la inmensa mayoría de los nuevos barrios y calles que fueron surgiendo refirieron, mayoritariamente, a la geografía nacional, de hecho nombres de ríos, montañas y la flora y fauna del país nombraron las nuevas poblaciones y lugares públicos:

El cambio de nombre de los bienes o lugares enumerados en el inciso primero podrá hacerse mediante decreto supremo fundado del Ministerio del Interior, previo informe de la Municipalidad respectiva, y sólo procederá en los siguientes casos: // a) Cuando en una misma ciudad existan dos o más de ellos, de similar naturaleza, con el mismo nombre o uno semejante que induzca a confusión; // b) Cuando, teniendo denominaciones distintas, dos o más de ellos constituyan una unidad o uno sea la continuación o prolongación de otro, y se considere conveniente asignarles un solo nombre; // c) Cuando el nombre asignado no tenga representatividad o no se encuentre enraizado en la tradición histórico-cultural de la Nación o de la respectiva región, provincia o comuna; // d) Cuando el nombre cause agravio a los valores y tradiciones de la historia patria o de un país extranjero con el cual Chile mantenga relaciones diplomáticas, y // e) Cuando un nombre infringiere las normas señaladas en el subsiguiente inciso. Fuera de los casos previstos en el inciso anterior, el cambio de nombre de dichos bienes o lugares sólo podrá efectuarse por medio de ley. No podrán asignarse a los bienes y lugares a que se refiere el inciso primero de este número, denominaciones correspondientes al nombre de personas vivas o de personas jurídicas vigentes, de organizaciones o de grupos existentes, de ideologías o de movimientos políticos. $^{2}$

Tradicionalmente, las competencias sobre la nomenclatura radicaron en las municipalidades. A través del decreto que hemos citado se delegó en el Ministerio del Interior, previo informe municipal, las facultades en asuntos de nomenclatura. Resulta de suyo interesante que el decreto definiera expresamente la prohibición de utilizar nombres de personas naturales o

1 Bando 37 II zona naval de Talcahuano, 19-09-1973

2 Decreto Ley No 1571, 7-10-1976 
jurídicas existentes y de ideologías o movimientos políticos, aunque instando a la denominación de espacios públicos con nombres de personas o gestas que enaltecieran la nación. ${ }^{3}$

En el contexto de los nombramientos relativos a figuras de la dictadura, encontramos referencias muy específicas. El 6 de junio de 1975 se inauguró un jardín infantil en la población Oscar Bonilla, tanto la población como el preescolar se inauguraron con el nombre de un importante militar golpista muerto en un accidente. ${ }^{4}$ Bonilla fue ministro de Interior y Defensa durante los primeros años de la Junta Militar. Hasta hoy se pueden observar barrios y avenidas que han conservado el nombre de Oscar Bonilla en ciudades importantes como Santiago y Concepción.

Podemos señalar que, respecto de la nomenclatura, fueron particularmente importantes las intervenciones realizadas durante los primeros años de la dictadura. Estos cambios, de fuerte contenido ideológico, constituyeron una reacción situada en el marco del radical giro político posterior al golpe de Estado.

Detengámonos en la denominación Once de septiembre que adquirió, con el devenir de los años, el carácter de fecha simbólica y el nombre más significativo del régimen para inaugurar nuevas obras. ${ }^{5}$ Pese a ello, no fue de uso masivo y se prefirió aludir a los nombres históricos de militares y políticos de las dos guerras -la de Independencia y la del Pacífico- consideradas constructoras de la nacionalidad y del Estado. Veamos algunos ejemplos de esta denominación.

El nombre, referencia directa al golpe de Estado, se utilizó para denominar barrios periféricos de ciudades intermedias y pueblo pequeños. ${ }^{6}$ El uso de Once de septiembre como denominación de calles y barrios, si bien fue puntual, pervivió en pueblos pequeños y en una importante avenida capitalina; la fecha fue el vestigio público más importante de recuerdo de la dictadura.

En noviembre de 1975 se anunciaron los inicios de los trabajos de construcción de una importante avenida en la zona oriente de Santiago, diseñada como Nueva Providencia por los urbanistas y que fue denominada Once de septiembre en 1980. La construcción, aprobada desde 1973, encontró entonces la resistencia de algunos propietarios y de la dirección del metro:

Providencia es una comuna sin campamentos ni poblaciones de emergencia como las que abundan en otras del Gran Santiago. Tampoco tiene zonas rurales y, en general, es una pequeña ciudad totalmente edificada y urbana donde viven sus 110.000 habitantes, en medio de un comercio floreciente $y$ una actividad febril que se inicia desde temprano. [...] se han iniciado los trabajos preliminares (demoliciones $y$

3 Con respecto a este elemento cabe mencionar el Edificio UNCTAD III, devenido en Diego Portales, una referencia ideológica del régimen. La construcción de $13.300 \mathrm{~m} 2$ tardó 275 días con participación de voluntarios, posteriormente el Ministerio de Educación se trasladó al edificio y el complejo se denominó Centro cultural metropolitano Gabriela Mistral http://web.archive.org/web/20080520113449/http://www.edificiodiegoportales.cl/historia.php, consultado el 20 de agosto de 2013), el nombre fue recuperado durante la administración de Michelle Bachelet (Ley $N^{\circ} 20386,27-10-$ 2009).

4 Permanentemente se han planteado serias dudas acerca de la muerte accidental de Bonilla, quien había adquirido gran influencia y popularidad en los primeros meses tras el golpe y se mostró crítico con la política represiva que aplicaba el general Manuel Contreras a cargo de la DINA. Estas razones, se ha especulado, serían las que habrían motivado su "accidente" (Cavallo y otros, 2008: 84-87).

5 En febrero de 1974 se inauguró un gimnasio con la denominación de la fecha del golpe de Estado en un bastión de la izquierda chilena, Lota (Concepción) (El Mercurio, 18-02-1974: 17). Sin duda, en los lugares con una carga histórica tan marcada con el sector derrotado tras el golpe, era crucial insertar otras denominaciones y en este caso, que fueran completamente reconocibles con la nueva administración dictatorial, el nombre del gimnasio no pervivió.

6 En la prensa destacan inauguraciones del nombre en Los Ángeles en 1973 (El Mercurio, 10-09-1973: 29) y Nacimiento hacia 1975 (El Mercurio, 24-08-1975: 25), ambas en la provincia de Bío Bío. 


\section{expropiaciones) en lo que será la futura Avenida "11 de septiembre", a cargo de la} sociedad CORMU-Providencia $[\ldots]^{7}$

Estos ejemplos, tal vez los más significativos para los chilenos, son el punto inicial de una mirada más focalizada sobre estas intervenciones dictatoriales, cabría preguntarse por redenominaciones post 1973 en localidades, barrios y espacios urbanos.

El uso de la nomenclatura fue una práctica que la dictadura realizó para difundir su proyecto. Llegados a este punto, podemos destacar que esta forma de intervención del espacio público no fue priorizada por el régimen; las prohibiciones de las libertades civiles tuvieron mucho mayor impacto y fueron desarrolladas con más interés por parte de las autoridades. Aun así, podemos considerar que estas formas de intervención estuvieron entre las estrategias de dominio absoluto del espacio público que la dictadura impuso.

Otra de las formas de dominación política sobre el espacio público se refiere a los elementos geosimbólicos del mismo, revisemos tres elementos que ejemplifican esta estrategia de dominación territorial: el Palacio de La Moneda, las casas de Salvador Allende y las de Augusto Pinochet.

\section{Carácter geosimbólico de La Moneda}

Junto a la historia y la antropología, disciplinas que hemos visto han abordado la cuestión del espacio público, también lo ha hecho la geografía con reflexiones múltiples. Por cuanto a nuestro trabajo interesa, es útil lo señalado por Bonnemaison acerca de la construcción de los "geosímbolos", 8 que interrelaciona el lugar con la dimensión cultural e histórica que las comunidades otorgan a éste:

El geosímbolo es un marcador espacial, un signo en el espacio que refleja y forja una identidad [...]. Los geosímbolos marcan el territorio con símbolos que arraigan las iconologías en los espacios-lugares. Delimitan el territorio, lo animan, le confieren sentido y lo estructuran. ${ }^{9}$

Evidentemente, el concepto es trabajado para subjetivar los espacios, dotándolos de la posibilidad de constituir historicidad en función de las identidades que se le confieren.

Para la sociedad existen elementos referenciales de una comunidad, la geografía cultural ha definido estos elementos como geosímbolos. En nuestro caso, edificios como La Moneda constituye un geosímbolo del Chile republicano, pues es una referencia para marcar la materialidad de lo político, para escenificar la ritualidad republicana, apartando el caos y construyendo un orden discursivo. Es un espacio identitario de lo político.

La Moneda, en cuanto geosímbolo, tiene un peso de vital importancia en el imaginario de los ciudadanos y lo que acaece en este lugar impacta y refleja el momento político. Buscamos analizar, a través de la manera en que se intervino el palacio, los signos que denotaron las concepciones del régimen militar.

La centralidad de este análisis es la interpelación sobre las prácticas políticas y su correlato en el espacio público, tan significativo en el caso de los lugares con carga política. Sobre esto, nos preguntamos cómo las decisiones intervienen el espacio y cómo éste puede incidir en las

\footnotetext{
7 El Mercurio, 6-11-1975: 17

8 Los estudios de Jöel Bonnemaison (2000), visitados por la geografía mexicana y chilena que hemos revisado, comprenden la geografía desde la construcción cultural que le dan las comunidades a los espacios que habitan, desde esta perspectiva asumimos el traslado del concepto a los estudios propiamente históricos, con el afán de sintetizar un fenómeno presente en las sociedades y la construcción de sus identidades nacionales.

9 Bonnemaison en Raichenberg y Heau-Lambert, 2008: 179
} 
prácticas políticas; en definitiva, nos preguntamos por el diálogo dado entre espacio y acción. En el entendido de la excepcionalidad, estudiamos La Moneda bombardeada, quemada e intervenida.

El espacio público impone condiciones para la acción política y, en ese sentido, tiene carácter normativo, precisamente, desde ese marco podemos evaluar el diálogo que se produce entre ese lugar y el significado que le entregan los actores. También tiene capacidad de sincronizar, en tanto que el espacio público convoca multiplicidad de voces, en muchas ocasiones contradictorias pero que, reunidos por el aspecto normativo que exige el uso del espacio público, deben sincronizarse dialógicamente.

En la experiencia dictatorial estas características se ven enturbiadas por la prohibición propia de ese tipo de gobierno. La primera intervención de la dictadura se dio justamente con el bombardeo al palacio de gobierno, con el que se inauguró el período pinochetista.

La reparación del palacio de La Moneda representó también una reconstrucción del espacio simbólico del poder en Chile. Este edificio se ha identificado con el gobierno, la casa del poder desde que nace la República. La reparación, en plena dictadura, implicó una nueva casa hecha a la medida de la instalación dictatorial. La reinvención de ese espacio y de la relación entre espacio y práctica política se reinventó como el símbolo del poder de las clases oligárquicas del país, representado en La Moneda:

Después del deterioro y posterior incendio que sufrió La Moneda, precisamente en la parte construida por Toesca, ya que el Ministerio de Relaciones (Exteriores) fue añadido en este siglo, aunque con mucha fidelidad al estilo impuesto por su arquitecto original [...] // La Moneda tuvo un significado histórico, pero además fue la obra civil de mayor envergadura que dejó la época anterior a la Independencia. Es por eso que ahora mucha gente espera verla reconstruida, con la mayor fidelidad posible en cuanto a la parte arquitectónica, que interpretaba tan bien el gusto por la sobriedad que caracteriza al arte chileno. ${ }^{10}$

En 1976 Pinochet visitó las obras de reconstrucción del palacio. La sincronización que requería este espacio geosimbólico, que representaba la unidad de la nación y la normalización de las múltiples voces que ese espacio significaba para el Chile republicano, quedó desplazado. La voluntad no convocante ni sincronizante de la reconstrucción generó un desplazamiento desde la idea republicana a la dictatorial, produciendo un concepto de unidad nacional excluyente, hegemónica y belicista.

En suma, la restauración/reinvención del palacio nos habla de la relación entre espacio y práctica política, reflejada por la reconstrucción y el proceso de alhajamiento que tuvo lugar bajo la lógica militar, el indicador más elocuente es, probablemente, la construcción del búnker. La decoración de inicios del siglo XIX reflejó el interés por relatar el influjo de Portales y su descendencia política, la que derivaría en los militares y civiles comandados por Pinochet.

El uso del palacio fue también muy importante durante la visita del papa Juan Pablo II, quien posó junto a Pinochet y sus ministros en La Moneda. Esta visita fue de vital importancia para la imagen del dictador, tremendamente maltrecha tras el intenso ciclo de protestas desarrollado desde 1983, hasta el punto de hacer tambalear el régimen. La visita papal se produjo en el contexto de la mediación del pontífice en los conflictos limítrofes ente Argentina y Chile:

Se sabía que antes de concurrir al primer acto masivo, el de los pobladores, el Papa debía visitar La Moneda. Se trataba, según la Comisión Papal, de un acto protocolar de no más de una hora de duración, incluido un encuentro a solas con Pinochet, por

10 Ercilla, No 1992: 43 
espacio de 30 minutos. Pero el pontífice se salió del libreto, seguramente inducido por su anfitrión. Ante los asombrados ojos de muchos chilenos, que seguían la transmisión televisiva, el Papa apareció en el balcón de La Moneda acompañado del general Pinochet [...] El hecho provocó estupor entre los corresponsales extranjeros, quienes en los corrillos del Hotel carrera comentaban: "el daño que esto podía hacer a la figura del Papa en Europa". Uno de estos periodistas despachó para su revista: "El Papa oró con Pinochet en el lugar donde fue asesinado el Presidente Allende. ${ }^{11}$

Las imágenes que se fabricaron en el palacio de La Moneda fueron bien elocuentes acerca de la importancia que Pinochet le dio al evento. En este caso, el dictador se presentó en traje civil junto al Papa. El saludo incluyó a la banda de la Escuela Militar y a quince mil adherentes de la dictadura, reunidas en la Plaza de la Constitución. Esta acción le valió críticas al pontífice por parte de diversos personeros. ${ }^{12}$ La imagen, en el patio de los naranjos del edificio, es la de un evento masivo al interior del palacio, aunque en términos reales estuvo acotado a un breve saludo papal.

La Moneda fue significada por la dictadura como un escenario para mostrar el mensaje político e ideológico del régimen. Sin duda se hicieron muchos esfuerzos por identificar el geosímbolo político con la figura de Pinochet y su régimen.

\section{Los espacios presidenciales}

Sin duda, las casas de las figuras presidenciales del período han significado una serie de hechos políticos y representaciones simbólicas de los regímenes que han encabezado. Es por ello que, consideradas como espacios privados, las podemos incluir en la articulación del devenir político del país durante el período dictatorial, tanto en la funcionalidad que tuvieron, como en la imagen que se les asignó por parte de la prensa y los discursos políticos que ella vehiculizó.

Este punto versa acerca de las propiedades donde residieron las principales figuras políticas de finales del siglo pasado: Salvador Allende y Augusto Pinochet. Buscamos analizar estas casas en función del rol político que tuvieron, y la imagen que se construyó acerca de ellas en los diversos y contrapuestos discursos políticos del período que tratamos en esta investigación.

La prensa oficialista fue particularmente expresiva en dar detalles acerca de estos lugares, que aunque privados, dada la función pública de sus moradores, fueron de interés para toda la población. Junto a la prensa, los escritos del periodismo de investigación y los textos testimoniales dan señales de los sucesos que tuvieron lugar en estos inmuebles, y que afectaron la vida política nacional.

\subsection{Residencias presidenciales de Salvador Allende}

Para el imaginario nacional, las casas presidenciales tomaron gran importancia en tanto que referían, y contradecían en el caso de Allende, la pertenencia a las clases sociales más pudientes del país. A costa de ello, la prensa y la opinión se volcó a construir relatos dirigidos a los ciudadanos. Recién acaecido el golpe de Estado, la prensa describió detalladamente la casa de Allende en calle Tomás Moro ${ }^{13}$ : veinte habitaciones, los ornamentos, además de señalar,

11 Análisis, No 169: 7

12 Cavallo, Salazar y Sepúlveda, 2008: 591-596 señalan que la visita papal a La Moneda fue planificado por el gobierno para presentar a Pinochet en palacio con el pontífice, en un contexto de "baño de masas", todo ello sin el conocimiento de la Iglesia Católica, cuestión que tensó las relaciones entre ambas instituciones.

13 La casa de la Avenida Tomás Moro, en Las Condes (Santiago), fue adquirida por el Estado en 1971 para ser la residencia familiar de los presidentes chilenos. Fue bombardeada por los mismos aviones que hicieron lo propio en el palacio de La Moneda el 11 de septiembre de 1973 (Verdugo, 1998: 143-146). 
puntualmente, la gran cantidad de comida y licores encontradas en la vivienda. Se destacaba el daño que sufrió la casa en el frontis, tras ser bombardeada con obuses y cohetes:

Aunque es lógico pensar que el Jefe de Estado viva bien, y nadie piense que debe pasar necesidades, la residencia de Tomás Moro resultaba un contrasentido para quien se proclamaba líder de los trabajadores y que constantemente zahería a "los momios del barrio alto". Había en los salones una saturación de brocatos, alfombras, porcelanas, marfiles, vajillería y cristalería europeos. En los dormitorios, los closets de muro a muro se mostraban colmados de lujosos abrigos, vestidos y zapatos importados de mujer. El ex mandatario disponía de un closet para sus abrigos. Al moverse la puerta de corredera de la ropa emanaba un fuerte perfume. // [...] En ese momento también resultaba de humor negro lo que Allende dijese a los mineros de Chuquicamata el 3 de marzo de 1972, según versión de la OIR: "Yo no soy un puritano torpe y exagerado. Me tomo media botella de vino al día, por lo menos, pero me lo tomo a la hora de almuerzo o a la hora de comida. Tomo un pisco antes de almuerzo y un pisco antes de comida. A veces me tomo un whisky, no siempre, porque es muy caro. ${ }^{14}$

La casa de Tomás Moro fue convertida en un asilo de ancianos. ${ }^{15}$ Una constructora realizó las reparaciones y luego se redistribuyó el espacio para albergar setenta y tres ancianos indigentes. La mujer del general Gustavo Leigh, Gabriela García, pidió ayuda a la comunidad para implementar el asilo de ancianos, ya que el Servicio Nacional de Salud no tenía fondos. En octubre de 1974 se inauguró oficialmente el nuevo hogar de ancianos de Tomás Moro. A la ceremonia asistió Leigh y el almirante Merino. La residencia pasó a llamarse "Nuestra Señora de Los Ángeles", atendido por monjas de la congregación de San Vicente de Paul.

El Cañaveral ${ }^{16}$ fue otra de las propiedades asociadas a la figura de Salvador Allende. Tras ser expropiado a Miria Contreras, la secretaria del Presidente socialista, El Cañaveral fue transformado completamente, pues funcionó como hogar de niños durante largo tiempo, finalmente dificultades económicas impidieron que subsistiera como tal. Una vez acabada la dictadura, la propiedad fue devuelta a la hija de su propietaria y convertida en un centro de eventos.

La prensa oficialista señaló que el GAP, la guardia personal de Allende que estaba en El Cañaveral, ${ }^{17}$ huyó antes que llegaran las fuerzas militares. En esta residencia no se registraron grandes daños, pero se halló dinero en grandes cantidades, comida, ropa y bebidas, whisky y vino, además de amplia literatura marxista y fotografías del ex Presidente. Se describía la presencia de dependencias para la fabricación de armas y explosivos:

El que fuera lugar de descanso y distracción del ex Presidente Allende -además de campo de entrenamiento de guerrilleros- sirve, desde la semana pasada, de pacífico y recatado hogar de menores en situación irregular. Tan radical cambio se produjo en la villa El Cañaveral, cuyo nombre también fue reemplazado: ahora se llama "Hogar

14 Ercilla, No 1991: 25

15 La Corporación Nacional de Protección a la Ancianidad (Conapran) dirigida por la esposa del comandante en jefe de la $\mathrm{FACH}$, se encargó del recinto hasta el día de hoy. El decreto No 165 le entregó la casa por diez años y en 1980 , a perpetuidad. El decreto No 2130 lo designó monumento histórico, impidiendo la enajenación o venta del inmueble, a menos que el comprador sea el Estado.

16 La casa fue edificada en el camino a Farellones (Santiago). Perteneció a la hermana de Miria Contreras, quien la vendió a la secretaria de Allende. Allende realizaba reuniones más íntimas allí. A días del golpe Pinochet fue informado allí de los planes de plebiscito que tenía Allende para sortear la crisis política. http://www.salvadorallendegap.com/categorias/tesimonios/testimonio_cespedes_rivera.html, consultado el 15 de noviembre de 2012.

17 GAP: Grupo de Amigos Personales, fundamentalmente fue una brigada de seguridad del Presidente, conformada por militantes del MIR y el Partido Socialista. La mayoría de este grupo resultó ejecutado en el ataque a La Moneda o en los días posteriores (Pérez, 2000; Quiroga, 2001). 
Javiera Carrera". // En la inauguración oficial -viernes 21-, las nuevas autoridades destacaron lo simbólico de la ceremonia. Por qué lo que antes fuera sede de íntimas y procaces reuniones quedó destinado a educar en el amplio sentido de la palabra a un centenar de niños huérfanos o que sus padres abandonaron. ${ }^{18}$

En octubre de 1973 se informó del nuevo uso que se dio a la casa del Cañaveral: por orden de la junta se transformó en un centro abierto para niños en situación irregular. Al respecto, la nota de prensa insistía en las condiciones en que se encontró la vivienda tras el golpe de Estado y se expuso el uso de la casa para entrenamiento guerrillero. Administrado por el Ministerio de Justicia, el hogar de niños se llamó "Javiera Carrera": "Donde antes se escucharon, amortiguados por el rumor del río, las voces de la orgía, se oirán risas infantiles y se desarrollará la normal actividad de un jardín escolar. Esto vale por una lección nacional de ética y de recuperación de sus valores". ${ }^{19}$

En diarios y revistas, durante las primeras semanas posteriores al golpe de Estado, se exhibieron profusamente las imágenes de destrucción de las dos residencias de la familia Allende. Especial interés despertaron los arsenales hallados en las viviendas, supuestamente parte del denominado Plan Z, destinados a armar a los partidarios de la Unidad Popular para generar una guerra civil en el país. ${ }^{20}$ Resulta muy extraño que las casas de Salvador Allende fueran utilizadas para cobijar arsenales, considerando que allí residía su familia.

Luego de 1974, las casas de Allende dejaron de aparecer en la prensa y revistas. Huelga decir que múltiples obras de arte y objetos históricos que se encontraban en estas residencias no han podido ser recuperadas. Es sabido que, entre otras obras, las casas de Allende albergaban cuadros de Miró, Guayasamín y Siqueiros. Se estima que muchas de ellas pueden estar en casas de particulares, ya que las residencias de Allende fueron saqueadas tras el golpe de Estado. ${ }^{21}$

Sin lugar a dudas, la amplia cobertura de los medios oficialistas estuvo al servicio del interés comunicacional de la dictadura para desprestigiar al régimen de la Unidad Popular y con ello, especialmente, denostar la imagen de Salvador Allende. Esta política de la dictadura contribuyó a construir la idea de enemigo interno, representado en la máxima referencia política del sector identificado como enemigo, para ello se escenificó su modo de vida, supuestamente contrario a lo que declaraba el discurso socialista.

\subsection{Las casas de Augusto Pinochet}

Pinochet también reflejó en su modo de vida una referencia del proyecto ideológico que representaba. Ahora analizaremos algunos de los aspectos que relatan esos elementos que son parte de la vida política de un líder. También en este caso la prensa nos ayuda a recabar antecedentes para realizar interpretaciones y relaciones en torno a este tópico.

En 1984 La revista Cauce publicó fotografías de una de las residencias de Augusto Pinochet, provocando un gran remezón en la opinión pública. La casa del exclusivo barrio de Lo Curro (Santiago) impactó por la fastuosidad que mostraban las imágenes. El artículo de la periodista Mónica González resumía a la fecha de publicación las propiedades de Pinochet:

18 Ercilla, No 2004: 14

19 El Mercurio, 27-12-1973: 3

20 Huneeus, 2005: 85-86

21 En 1971 artistas e intelectuales resolvieron la creación de un museo internacional, con ese motivo, más de 500 obras fueron donadas a Allende y al Estado de Chile. En este contexto se perdieron de importantes obras debido al saqueo a las casas de Allende y a La Moneda, dañando severamente el patrimonio nacional. http://www.mssa.cl/sobreel-museo/, consultado el 12 de junio de 2013. 
No es posible establecer con exactitud cuánto costaron al erario nacional la denominada "casas de los presidentes", en Lo Curro, la casa que el general Pinochet ocupa algunos fines de semana en el Cajón del Maipo (San Alfonso), la casa que el gobernante arrendaba en Luis Thayer Ojeda y hoy ocupa uno de sus hijos como propietario, la casa de los comandantes en jefe del ejército en la Avenida Presidente Errázuriz, los trabajos de remodelación de la casa de Bucalemu [... $]^{22}$

Es interesante constatar, más allá de lo oneroso de la vivienda de Lo Curro, que las características de la mansión eran las de una verdadera fortaleza. Además de la lógica militar reinante en la idea arquitectónica, se denotaba el interés por la funcionalidad en términos de seguridad, lo que indicaría la preocupación del ex dictador por resguardar su lugar de residencia familiar de eventuales ataques.

El fundo Los Boldos, en Bucalemu ${ }^{23}$ (Valparaíso) corresponde a una hacienda de arquitectura hispano criolla, destacada como la casa donde nació el presidente José Manuel Balmaceda (1886-1891). En 1978 el lugar pasó a manos del Ejército y fue destinado al uso recreacional del comandante en jefe, a la sazón, el mismo Augusto Pinochet, quien la utilizó como casa de veraneo. En 2004 fue entregada al municipio de Santo Domingo para usos museográficos.

Otra vivienda importante en la vida política del dictador es la ubicada en el Cajón del Maipo (Santiago), en el sector conocido como El Melocotón. El atentado a Pinochet del 7 de septiembre de 1986 se produjo cuando volvía de su casa en esa zona, la residencia fue utilizada para el descanso en las cercanías precordilleranas de Santiago, el dictador solía utilizar esta vivienda los fines de semana, cuestión que el FPMR aprovechó para atacar la comitiva de familiares y escoltas. Esta fue una de las acciones más sonadas del grupo subversivo.

La parcela de El Melocotón fue habilitada a principios de los ochenta para el descanso de la familia Pinochet y tras el atentado de 1986 fue reemplazada como vivienda de descanso por el fundo Los Boldos en Bucalemu. El Melocotón fue comprado con ahorros personales de Pinochet, pero investigaciones posteriores ponen en duda el valor de la propiedad comprada. ${ }^{24}$

Pinochet caracterizó la doctrina de seguridad nacional en su forma de habitar. Creemos que esto se condice perfectamente con la siempre buscada identificación de su figura personal con el régimen político que encabezaba, como ya hemos visto en su relación con el edificio de La Moneda. En el caso de las residencias personales, esto puede aplicarse a la casa de Lo Curro, por las características constructivas del edificio; en el caso de El Melocotón primó la dificultad en el acceso al lugar, cuestión que revela el temor a un ataque, como efectivamente ocurrió; la situación de Bucalemu no obedece a los dos casos anteriores y tal vez su interés fue dada por la identidad histórica.

Las residencias, tanto de Allende como de Pinochet, se constituyeron en parte del debate que develaba las diversas maneras de habitar en propiedades públicas y que pertenecían al patrimonio nacional. Mientras el primero se conecta con la tradición aperturista de utilizar su residencia para la actividad política, y de revestirla de elementos que le añadieron valor

22 Cauce, No 2, 1984: 17

23 Tras la expulsión de la Compañía de Jesús, en 1767, la casa pasó a manos de Pedro Fernández Balmaceda, abuelo del ex presidente Balmaceda. En 1865 fue adquirida por Claudio Vicuña, quien la modernizó al gusto francés de la época. En 1978 fue expropiada a favor del Ejército de Chile. http://www.ciudadliberal.cl/hacienda-bucalemu-la-cunade-balmaceda/, consultado el 12 de junio de 2013.

24 En el marco del caso Riggs se investigan las irregularidades de la fortuna personal de Pinochet, lo que significó el embargo de la propiedad y su traspaso, a día de hoy, a la Universidad San Sebastián, que la habilitó como casa de montaña. http://ciperchile.cl/2012/07/10/los-negocios-de-pinochet-que-beneficiaron-a-las-universidades-mayor-y-sansebastian, consultado 16 de diciembre de 2013. 
patrimonial; el segundo lo hizo en la lógica del cubil militar que se cierra frente a lo público, expresando su idea de amenaza a la seguridad.

Fuera de los espacios geosimbólicos de carácter político que hemos revisado, se encuentran los espacios públicos que fueron ocupados por la dictadura y sufrieron un proceso de (re) significación, ello es parte del ambiente social y político que la instalación pinochetista tuvo en el país.

\section{Espacios ocupados y significado por el régimen}

En función del cambio absoluto de signo político, luego de 1973, la rica vida social y política chilena previa a esa fecha, se expresaba, en una parte importante, en los inmuebles que las organizaciones políticas y sociales constituyeron hasta el momento del golpe de Estado.

Cabe señalar el destino que se les dio a la gran cantidad de edificios de los partidos políticos y sindicatos, desde el golpe de Estado en receso político y con prohibición de funcionar. Estos edificios fueron confiscados y entregados para el uso de alguna dependencia pública o alguna acción social en el mejor de los casos: algunos fueron asaltados y saqueados, otros pasaron al control de organismos del ejército, incluidas los centros de tortura. ${ }^{25}$

El Diego Portales fue utilizado como sede de gobierno hasta la entrega del reconstruido palacio de La Moneda, ocurrida en 1981. Las imágenes más conocidas de la Junta Militar recién instalada en el gobierno, son las hechas en este edificio. Los rostros de los golpistas, devenidos en ejecutores del poder político, se dejaron ver por primera vez en el salón de plenarios de ese edificio. Pinochet recibió la banda presidencial en septiembre de 1974 de manos de mujeres en el salón de plenarios:

Agradecidas por haber escuchado los ruegos que le hicieron hace un año las mujeres de Chile para que tomara la decisión del 11 de septiembre, un grupo de damas comerciantes de la Vega Municipal obsequió ayer al Jefe Supremo de la Nación, general Augusto Pinochet una hermosa banda presidencial. // El acto que tuvo contornos emotivos se realizó en el salón en que se reúne el Consejo de Gabinete, en el piso vigésimo segundo del edificio Diego Portales. ${ }^{26}$

La banda presidencial es un símbolo de la presidencia. El once de septiembre de 1974 estas dirigentes del departamento femenino del sindicato de la Vega Municipal de Santiago, entregaron la banda realizada por las monjas adoratrices, que portaba una imagen de la virgen del Carmen. Con esta ceremonia se graficaron los elementos, que en los primeros años de la dictadura, acompañaron la imagen del régimen, vinculado a mujeres organizadas corporativamente, presentes continuamente en el edificio Diego Portales y refiriendo un discurso nacionalista en sus símbolos. ${ }^{27}$

Otro tipo de espacio significado por la dictadura tuvo que ver con los constituidos para la conmemoración, es decir, lugares de alta carga ideológica que intentaron construir la representación simbólica del régimen y en ese sentido, fueron utilizados en diversos actos y ceremonias. ${ }^{28}$

25 Es el caso del inmueble de Londres 38, antigua sede comunal del Partido Socialista. En este edificio funcionó un grupo de la DINA hasta fines de 1974, hoy funciona allí la Casa de la Memoria, destinada a la recuperación del testimonio histórico de las víctimas de la dictadura. http://londres38.cl/1937/w3-propertyvalue-32013.html, consultado el 5 de enero de 2013.

26 El Mercurio, 11-9-1974: 77

27 Kirkwood, 2010: 161-163

28 En este sentido hemos podido identificar el "Altar de la Patria" y la "Llama de la Libertad" como los espacios fundamentales -aunque no los únicos- pues hemos identificado algunos actos eventuales en la Plaza Yungay y en el Templo Votivo de Maipú, quedando por referir lugares similares en regiones y localidades urbanas. 
El once de septiembre de 1975 , en un nuevo aniversario del golpe de Estado, la Junta Militar encendió la "Llama de la Libertad" en la Plaza Bulnes, frente a La Moneda. Ese acto conmemorativo del asalto al palacio, vino a significar la imagen más potente del discurso nacionalista presente entre los distintos grupos que daban apoyo al régimen. En un acto masivo y durante la ceremonia, Pinochet señaló:

La libertad no es un don gratuito. Hay que conquistarla día tras día, porque a todas horas trabajan los enemigos de ella para destruirla o desvalorizarla en nuestras conciencias [...] Por último, hay que entregarla a nuestros descendientes pura y limpia, para que ellos reciban el más preciado legado y sepan cuidarla para sus hijos $^{\prime 29}$

El uso del fuego, en su significado de purificación y renovación, no ha sido habitual en la política chilena, siempre vinculada a ceremonias racionalistas en su republicanismo. Sin duda esta ceremonia trajo a colación la sospecha de filiación nacionalista del régimen militar. Esta instalación se realizó para marcar la identidad del nuevo régimen y en cuanto tal era necesaria la representación de un nuevo orden sobre las "cenizas" del anterior.

La dictadura, como ya hemos señalado, buscó referenciarse en el discurso histórico tradicional, conservador y nacionalista; en ese relato es que instaló su proyecto histórico y en ese sentido ocupó espacios públicos donde escenificar esas ideas. El Altar de la Patria fue la máxima representación del ideario nacionalista del proyecto dictatorial, cargado de elementos que hacen alusión al militarismo como vector de la nacionalidad y constructor del estado nacional:

Miles de personas se reunieron ayer en el corazón de la capital para presenciar la solemne instalación de los restos de Bernardo O'Higgins en el "Altar de la Patria" en la Plaza del Libertador. El acto cívico-militar, presidido por el Jefe de Estado, contó con la participación masiva de estudiantes, organizaciones comunitarias, clubes de huasos, efectivos de las Fuerzas Armadas y un público numeroso que concurrió, en una atmósfera de recogimiento, a la emotiva ceremonia. ${ }^{30}$

En julio de 1979 se terminaron las obras del Altar de la Patria, edificación y mausoleo que albergó las tumbas de los más insignes militares de la historia chilena, este monumento fue ubicado en el paseo Bulnes justo frente a La Moneda. En la Alameda se construyó el subterráneo que definió, en su planta a pie de calle, el altar propiamente tal, consistente en estatuas conmemorativas de los héroes de la patria.

Así entonces, es posible acceder a una comprensión de la dictadura como articulación política pública, constructora de un discurso que intentó referir un proyecto para todos los ciudadanos y que, en definitiva, es lo que buscaba a través de la escenificación de sus conmemoriaciones.

\section{Conclusiones}

Una vez presentados los elementos que indican las fuentes históricas en torno al problema planteado cabe realizar algunas reflexiones finales, haciendo una salvedad, el cariz inicial del presente estudio, visto la necesidad de profundizar el análisis en otros espacios urbanos, fuera del centro cívico santiaguino.

La dictadura utilizó diversos mecanismos para materializar su proyecto ideológico en el espacio público, tanto las intervenciones en la nomenclatura como las redefiniciones en La Moneda, el más importante geosímbolo político de la nación contribuyeron a ese objetivo.

29 El Mercurio, 12-9-1975: 33

30 El Mercurio, 21-08-1979: C1 
El uso de la nomenclatura fue una práctica que la dictadura realizó para difundir su proyecto. Debemos destacar que esta forma de intervención del espacio público no fue priorizada por el régimen; las prohibiciones de las libertades tuvieron mucho mayor impacto y fueron desarrolladas con más interés por parte de las autoridades. Aun así, podemos considerar que estas formas de intervención estuvieron entre las estrategias de dominio absoluto del espacio público que la dictadura impuso.

En relación a las intervenciones en el Palacio de La Moneda, este fue significado por la dictadura como un escenario para mostrar el mensaje político e ideológico del régimen. Sin duda se hicieron muchos esfuerzos por identificar el geosímbolo político con la figura de Pinochet y su régimen. También la resistencia y la oposición reconocieron en el edificio un espacio a recuperar para el imaginario republicano y democrático que adoptó como reivindicación en su discurso.

Las residencias, tanto de Allende como de Pinochet, se constituyeron en parte del debate que develaba las diversas maneras de habitar en propiedades públicas y que pertenecían al patrimonio nacional. Mientras el primero se conecta con la tradición aperturista de utilizar su residencia para la actividad política, y de revestirla de elementos que le añadieron valor patrimonial; el segundo lo hizo en la lógica del cubil militar que se cierra frente a lo público, expresando su idea de amenaza a la seguridad.

Por otra parte, las características y usos de las residencias presidenciales nos dan cuenta de las ideas políticas que estaban en juego; a través de sus usos nos damos cuenta de las visiones que se quisieron imponer a la sociedad o las reacciones frente a la violencia política. Lo mismo se evidencia en relación a los edificios y espacios de uso público que construyó o resignificó el régimen.

De esta forma, la constitución de espacios públicos, para escenificar las conmemoraciones del proyecto dictatorial, formó parte de una política del régimen militar. La dictadura comprendió rápidamente que debía construir un imaginario que identificara sus ideas con la nación y, a través de ello, la población pudiera reconocer un discurso y una intención política clara.

Finalmente, los mecanismos de significación del poder político dictatorial pueden ser rastreados en diversos escenarios: edificios y monumentos, residencias, plazas, calles y barrios, entre muchos otros. Ahora bien, todo ello nos ha llevado a analizar el uso e intervención del espacio público, entendido como el ágora donde se realiza el debate ciudadano, hemos querido presentar algunos elementos que nos explican cómo se desarrollaron esos cambios, abriéndose una importante línea de investigación a profundizar en futuras investigaciones. 


\section{Bibliografía}

\section{Fuentes}

Bando 37 II zona naval de Talcahuano, 19-09-1973

Decreto Ley No $1571,7-10-1976$

Decreto No 165 de 1975

Decreto No 2130 del 26 de diciembre de 2006

Ley $\mathrm{N}^{\circ} 20386,27$ de octubre de 2009

El Mercurio, 1973-1989

Revista Análisis

Revista Cauce

Revista Ercilla

\section{Libros y artículos}

AUGÉ, Marc. Los "no lugares" espacios del anonimato, Una antropología de la sobremodernidad. Barcelona, España. Gedisa. Septiembre del 2000. 125 p. ISBN: 84-7432-459-9.

BIANCHINI, María. Chile, memorias de La Moneda. La (re) construcción de un símbolo político. Madrid, España. UAM-IEPALA, 2012. 327 p. ISBN: 978-84-8344-352-5.

BONFIL, Guillermo. México profundo: una civilización negada, México D.F. Grijalbo. 1989. 250 p. ISBN: 968-419-929-5.

BONNEMAISON, Jöel. La géographie culturelle. París, Francia. Editions du cths. 2000. 152 p. ISBN: 27355045819782735504589.

BORJA, Jordi. La ciudad conquistada. Madrid, España. Alianza. Julio de 2010. 381 p. ISBN: 8420641774.

ERRÁZURIZ, Luis. La dictadura militar en Chile. Antecedentes del golpe estético cultural. Latin American Research Review, Vo. 44, No 2. 2009.

CASTELLS, Manuel. La ciudad y las masas: sociología de los movimientos sociales urbanos. Madrid, España. Alianza. 1986. 567 p. ISBN: 8420680982.

CAVALLO, Ascanio, Manuel SALAZAR, Oscar SEPÚLVEDA. La historia oculta del Régimen Militar. Memoria de una época. Santiago de Chile. Uqbar. 2008. 725 p. ISBN: 978-956-8601-34-8.

DELGADO, Manuel. El animal público. Hacia una antropología de los espacios urbanos. Barcelona, España. Anagrama. 1999. Mayo de 1999. ISBN: 84-339-0580-5.

HEAU-LAMBERT, Catherine y Enrique RAJCHENBERG. "Para una sociología histórica de los espacios periféricos de la nación en América Latina", Antípoda, No 7. 2008.

HUNEEUS, Carlos. El régimen de Pinochet. $3^{\circ}$ edición. Santiago de Chile. Sudamericana. Enero de 2005. 670 p. ISBN: 956-262-126-X.

KIRKWOOD, Julieta. Ser política en Chile. Las feministas y los partidos. $3^{\circ}$ edición. Santiago de Chile. LOM. 2010. 198 p. ISBN: 978-956-00-0169-6.

MUNIZAGA, Giselle. El discurso público de Pinochet. 1973-1976. Un análisis semiológico. Buenos Aires, Argentina. Clacso. Febrero de 1983. 105 p. 
NORA, Pierre. Pierre Nora en les lieux de mémoire. Santiago de Chile. LOM. 2009. 202 p. ISBN: 978-95600-0080-4.

PÉREZ Cristian. "Salvador Allende: Apuntes sobre su dispositivo de seguridad: El Grupo de Amigos Personales (GAP)", Estudios Públicos, Santiago de Chile, 79. 2000.

QUIROGA, Patricio. Compañeros. El GAP: la escolta de Allende. Santiago de Chile. Aguilar. 2001. 289 p. ISBN: 9789562391870.

SALAZAR, Gabriel. La violencia política popular en las "grandes alamedas", $2^{\circ}$ edición. Santiago de Chile. LOM. 2006. 352 p. ISBN: 956-282-826-3.

SALAZAR, Gabriel. Construcción de estado en Chile 1800-1837: democracia de los pueblos, militarismo ciudadano, golpismo oligárquico. 30 edición. Santiago de Chile. 2007. Sudamericana 550 p. ISBN:

9789562624138.

VERDUGO, Patricia. Interferencia secreta. 11 de septiembre. 70 edición. Santiago de Chile. Sudamericana. 1998. ISBN: 956-262-066-2.

\section{Referencias electrónicas}

Ciper Chile. "Los negocios de Pinochet que beneficiaron a las universidades Mayor y San sebastián", 2212-2012, <http://ciperchile.cl/2012/07/10/los-negocios-de-pinochet-que-beneficiaron-a-lasuniversidades-mayor-y-san-sebastian/>, visitado el 16 de diciembre de 2013.

Londres 38. "Su historia", <http://londres38.cl/1937/w3-propertyvalue-32013.html/>, visitado el 5 de enero de 2013.

Testimonios, "Testimonio de Manuel Céspedes Rivera" <http://www.salvadorallendegap.com/categorias/tesimonios/testimonio_cespedes_rivera.html/>, visitado el 15 de noviembre de 2012.

Paredes, Pablo. "Hacienda Bucalemu: la cuna de Balmaceda", 17-04-2013, <http://www.ciudadliberal.cl/hacienda-bucalemu-la-cuna-de-balmaceda/>, visitado 12-06-2013.

Museo de la Solidaridad Salvador Allende, <http://www.mssa.cl/sobre-el-museo/>, visitado el 12-062013.

Revista Auca. "Edificio símbolo en tiempo record. Vio la luz en 275 días", <http://web.archive.org/web/20080520113449/http://www.edificiodiegoportales.cl/historia.ph p>, visitado el 20-08-2013. 